\title{
BIOÉTICA E EUGENIA: PRESSUPOSTOS BIOPOLÍTICOS DA MANIPULAÇÃ̃O GENÉTICA
}

\author{
André Brayner de Farias ${ }^{1}$ \\ Universidade de Caxias do Sul (UCS) \\ https://orcid.org/0000-0002-8659-3921 \\ E-mail: abfarial@ucs.br \\ Eduardo Borile Júnior ${ }^{2}$ \\ Universidade de Caxias do Sul (UCS) \\ (iD) https://orcid.org/0000-0003-2671-1807 \\ E-mail: ebunior1@ucs.br

\section{Luis Fernando Biasoli ${ }^{3}$} \\ Universidade de Caxias do Sul (UCS) \\ (iD) https://orcid.org/0000-0001-7357-7079 \\ E-mail: lfbiasoli@ucs.br
}

\section{RESUMO:}

A partir da hipótese de que seres humanos modificados terão projetos de vida bem sucedidos, reflete-se quais seriam os pressupostos biopolíticos da manipulação genética na sociedade moderna. Considerando as teorias apresentadas por Michel Foucault (2005), Jürgen Habermas (2010), Michael J. Sandel (2013), Hans Jonas (2006) e Achille Mbembe (2014), identifica-se uma africanização genética da população menos favorecida economicamente. Neste cenário, conceitos de classe e raça se confundem e ampliam o preconceito social. Diante das novas tecnologias de engenharia genética, a manipulação gênica se apresentam como uma nova face do biopoder, uma vez que a ciência, agora, tem o poder de dar vida a partir da seleção de características consideradas superiores. Sustenta-se que a crítica em torno do processo de manipulação genética é necessária, pois abre a possibilidade de se debater acerca do reconhecimento mútuo como condição de vida, acima da identificação de raça ou classe, localização geográfica ou das demais características dos indivíduos que compõem a sociedade.

PALAVRAS-CHAVE: Biopolítica; Bioética; Biopoder; Eugenia; Racismo.

\section{BIOETHICS AND EUGENICS: BIOPOLITICAL ASSUMPTIONS OF GENETIC MANIPULATION}

\begin{abstract}
:
Based on the hypothesis that modified human beings will have successful life projects, the biopolitical presuppositions of genetic manipulation in modern society are reflected. Considering the theories presented by Michel Foucault (2005), Jürgen Habermas (2010), Michael J. Sandel (2013), Hans Jonas (2006) and Achille Mbembe (2014), a genetic Africanization of the economically disadvantaged population is identified. In this scenario, concepts of class and race are confused and social prejudice increases. Faced with the new technologies of genetic engineering, gene manipulation presents itself as a new face of biopower, since science now has the power to give life from the selection of characteristics considered superior. It is argued that the criticism surrounding the process of genetic manipulation is necessary as it opens the possibility of debating mutual recognition as a condition of life, above the identification of race or class, geographic location or other characteristics of the individuals that make up society
\end{abstract}

KEYWORDS: Biopolitics; Bioethics; Biopower; Eugenics; Racism.

\footnotetext{
1 Doutor(a) em Filosofia pela Pontifícia Universidade Católica do Rio Grande do Sul (PUCRS), Porto Alegre - RS, Brasil. Professor(a) da Universidade de Caxias do Sul (UCS), Caxias do Sul - RS, Brasil.

${ }^{2}$ Mestre(a) em Filosofia pela Universidade de Caxias do Sul (UCS), Caxias do Sul - RS, Brasil.

${ }^{3}$ Doutor(a) em Filosofia pela Pontifícia Universidade Católica do Rio Grande do Sul (PUCRS), Porto Alegre - RS, Brasil. Professor(a) de Filosofia da Universidade de Caxias do Sul (UCS), Caxias do Sul - RS, Brasil
}

FARIAS, André Brayner de; JÚNIOR, Eduardo Borile; BIASOLI, Luis Fernando. Bioética e eugenia: pressupostos biopolíticos da manipulação genética. Griot : Revista de Filosofia, Amargosa - BA, v.22 n.1, p.298-307, fevereiro, 2022. 


\section{O saber-poder}

“A medicina é um saber-poder que incide ao mesmo tempo sobre o corpo e sobre a população, sobre o organismo e sobre os processos biológicos e que vai, portanto, ter efeitos disciplinares $e$ efeitos regulamentadores" Michel Foucault

Toda análise acerca do futuro da humanidade está, imediatamente, sujeita ao erro. Não será diferente com o que, aqui, pretende-se apresentar. É evidente que toda promessa de evolução da espécie carece de entendimento, para ser comentada. Por isso, busca-se realizar uma análise biopolítica do racismo, a partir de pressupostos bioéticos, para identificar uma possível eugenia da sociedade moderna. Salienta-se que os balizadores da abordagem consideram os quatro princípios da Bioética ${ }^{4}$.

Etimologicamente, "Bioética" significa "Ética da vida". A área se concentra nos estudos filosóficos interdisciplinares que analisam questões de ética prática. Logo, como ponto de partida, ressalta-se a defesa da autonomia, da não maleficência, da beneficência e da justiça, focando-se em problemas biopolíticos (socioeconômicos, ambientais, raciais), consequências do debate das ciências humanas, para refletir acerca de um futuro processo de eugenia ${ }^{5}$. Ademais, reflete-se, criticamente, como o melhoramento genético pode garantir uma vida autônoma e justa, beneficiando, equitativamente, todas as camadas sociais sem prejudicar aqueles que, historicamente, são desqualificados pela cor da pele: a população negra.

Michel Foucault $(2005$, p. 285) recorda que o tema da raça ao invés de desaparecer se transformou no racismo de Estado. Nele, o poder do soberano dá direito de vida e de morte. "O direito de soberania é, portanto, o de fazer morrer ou deixar viver" (FOUCAULT, 2005, p. 287). É o biopoder, isto é, o poder sobre a vida, que controla as taxas de reprodução de uma população, a começar pelo domínio dos nascimentos e dos óbitos. Logo, a biopolítica não trata apenas do problema da fecundidade, mas também do problema da morbidade. "A biopolítica lida com a população, e a população como problema político, como problema a um só tempo científico e político, como problema biológico e como problema de poder". (FOUCAULT, 2005, p. 292-293)

Diante das novas tecnologias de engenharia genética, a manipulação gênica se apresenta como uma nova face do biopoder, uma vez que a ciência, agora, tem o poder de dar vida a partir da seleção de características consideradas superiores. "A soberania fazia morrer e deixava viver. E eis que agora aparece um poder que eu chamaria de regulamentação e que consiste, ao contrário, em fazer viver e em deixar morrer" (FOUCAULT, 2005, p. 294). Nesta perspectiva, a modificação genética atua como um mecanismo de regulamentação do corpo $^{6}$ visando controlar eventos fortuitos e compensar contingências.

\footnotetext{
${ }^{4}$ Princípio da autonomia (i), isto é, a capacidade de deliberar, agir livre e intencionalmente, com o conhecimento do que se faz sem influências externas; Princípio da não maleficência (ii), isto é, não causar dano, dor, sofrimento ou morte aos demais indivíduos, assim como não incapacitálos, não ofendê-los e não privá-los dos bens necessários à vida; Princípio da beneficência (iii), isto é, ações altruístas em benefício dos demais, bem como proteger e defender os direitos individuais, prevenir danos, remover as condições que podem causar danos, ajudar e salvar pessoas em perigo; Princípio da justiça (iv), isto é, a distribuição equitativa dos recursos, considerando, critérios democráticos.

${ }^{5}$ A eugenia foi um movimento que ambicionou aprimorar a raça humana geneticamente. Conforme Sandel (2013, p. 49), o termo significa "bemnascido" e foi cunhado em 1883 por sir Francis Galton (primo de Charles Darwin), que aplicou métodos estatísticos ao estudo da hereditariedade. Desde o início do século passado, defensores da prática lutaram, para impedir a reprodução de pessoas com genes considerados "indesejáveis". Nos EUA, foram criadas leis de esterilização involuntárias em deficientes mentais, prisioneiros e miseráveis. Segundo Sandel (2013, p. 50), estima-se que "mais de 60 mil americanos geneticamente "defeituosos' foram esterilizados".

6"Pode-se mesmo dizer que, na maioria dos casos, os mecanismos disciplinares de poder e os mecanismos regulamentadores de poder, os mecanismos disciplinares do corpo e os mecanismos regulamentadores da população, são articulados um com o outro" (FOUCAULT, 2005, p. 299).
} 


\section{O futuro da humanidade}

Inegavelmente, o pensamento do filósofo alemão Jürgen Habermas (2010) alcançou indiscutível relevância na comunidade filosófica mundial. A partir das reflexões do conceituado autor, questiona-se a possibilidade de, num futuro próximo, a dignidade humana estar condicionada à prévia aprovação genética. À guisa de problematização nesse tópico debate-se acerca das condições orgânicas e dos limites bioéticos questionando: de que forma os seres humanos podem influenciar na potencialidade da própria espécie?

O filósofo Michael J. Sandel (2013, p. 32; grifo do autor) acredita que "os argumentos que versam sobre a ética do melhoramento são sempre, ao menos em parte, argumentos em relação ao telos, ou objetivo". O estadunidense pondera que há uma encruzilhada no caminho da engenharia genética: de um lado há uma promessa; do outro há um dilema. "A promessa é que em breve seremos capazes de tratar e prevenir uma série de doenças debilitantes. $O$ dilema é que nosso recém-descoberto conhecimento genético também pode permitir a manipulação de nossa própria natureza" (SANDEL, 2013, p. 13). O autor categoriza como "inquietante" o fato de ser possível encomendar pessoas com traços genéticos específicos e crê que "a revolução genômica induziu a uma espécie de vertigem moral" (SANDEL, 2013, p. 15).

Contudo, embora a tecnologia possibilite o contínuo aperfeiçoamento da espécie, possuir uma boa genética não, necessariamente, implica em uma existência longa. Ademais, garantir uma vida sem doenças, também, não implica, necessariamente, numa vida saudável. Portanto, parece claro que o espectro de possibilidades é amplo. "Se essa situação parece perturbadora é porque os benefícios da bioengenharia seriam negados aos pobres não melhorados ou porque os ricos melhorados estariam de certo modo desumanizados?" (SANDEL, 2013, p. 18). Logo, considerase que as condições sociais de existência, tal como as experiências vivenciadas e os desejos individuais, impactam no desenvolvimento humano tanto quanto a genética.

Nesta perspectiva, Habermas (2010) apresenta questões acerca das condições socioculturais e das características biológicas, salientando que a influência de ambas, na construção dos planos individuais, muitas vezes, é desconsiderada pela literatura. Contudo, ele admite que isso pode ser justificado, uma vez que a problemática carece de processos políticos de autocompreensão, visto que os limites ainda são pouco definidos. Assim, a pretensão do autor parece ser a de traçar e impor fronteiras precisas acerca do debate sobre uma possível eugenia liberal? "Seria a eugenia censurável somente quando coercitiva? Ou haverá algo de errado mesmo com as formas não coercitivas de controlar a carga genética da geração seguinte?" (SANDEL, 2013, p. 53)

Parece evidente que as escolhas racionais, independentemente dos planos individuais, visam evitar o sofrimento e prolongar a condição da existência autônoma. Contudo, para Sandel (2013), a resposta não é tão óbvia. O autor acredita que as mudanças genéticas podem ameaçar o livre arbítrio da espécie humana.

Um dos aspectos da nossa humanidade que pode estar ameaçado pelo melhoramento e pela engenharia genética é nossa capacidade de agir livremente, por nós mesmos, graças a nossos próprios esforços, e de nos considerarmos responsáveis (ou seja, dignos de orgulho ou censura) pelas coisas que fazemos e que somos. (SANDEL, 2013, p. 26).

\footnotetext{
7 “A eugenia liberal se exime de tais ambições coletivas. Não é um movimento de reforma social, mas uma forma de pais privilegiados terem o tipo de filho que desejam e armá-los para o sucesso numa sociedade competitiva [...] Desde que as habilidades melhoradas sejam um meio válido "para todos os fins' e que, portanto, não direcionem a criança para nenhuma carreira ou modo de vida específicos, são moralmente aceitáveis". (SANDEL, 2013, p. 57).
} 
Ao encontro, Habermas (2010) salienta que a seleção de fatores hereditários indesejáveis e a otimização de fatores desejáveis carece de consenso. Quando se problematiza acerca da possibilidade de seleção intencional da vida, o tema ainda se apresenta nebuloso. Ademais, sobre isso, Habermas (2010, p. 37) sugere que,

depois que as reservas de tradição foram quase totalmente consumidas ao longo desse processo de civilização, as sociedades modernas também têm de regenerar as energias morais que as unem a partir de suas próprias resistências seculares.

Para Sandel (2013, p. 58), Habermas argumenta contra o uso da manipulação genética para melhoramentos de ordem não medicinal "porque viola os princípios liberais de autonomia e igualdade". Assim, busca-se salientar as análises político-econômicas sobre o impacto do melhoramento genético, visto que a tecnologia pode ser utilizada para gerar progresso produtivo e desenvolvimento econômico apenas para as camadas mais ricas da população. Vê-se que a promessa do aperfeiçoamento individual pode servir de premissa para uma seleção de características desejáveis a partir de padrões, previamente, estabelecidos via eugenia, visto que a prática reprodutiva se encontra com o novo consumismo (SANDEL, 2013, p. 54).

Em outras palavras, significa a manutenção de preconceitos, historicamente, enraizados na sociedade neoliberalista do terceiro milênio. "Qual é, afinal, a diferença moral entre projetar crianças segundo um propósito eugênico explícito e projetar crianças segundo os ditames do mercado?" (SANDEL, 2013, p. 55). Neste contexto, o biopoder não implica, necessariamente, na valorização da vida. A discrepância acerca da qualidade valorativa da existência humana, frente à lógica do poder, defende a manutenção de um sistema econômico, desprezando aqueles que o compõem.

Logo, como refletir a redução ontológica do ser humano? Como interpretar uma engenharia genética da vida biológica sendo colocada em prol do sistema econômico? Foucault (2005) enfatiza que o imperativo da morte é admissível no sistema de biopoder quando se busca a eliminação de uma raça ou espécie. $O$ francês recorda que na sociedade moderna "a raça, o racismo, é a condição de aceitabilidade de tirar a vida numa sociedade de normalização [...] o racismo é indispensável como condição para poder tirar a vida de alguém, para poder tirar a vida dos outros" (FOUCAULT, 2005, p. 306). Nessa perspectiva, o que pode ser entendido como "sociedade moderna"?

\section{A humanidade do futuro}

"A maior parte das injustiças no mundo contemporâneo resulta de vieses estruturais em grande escala, e não de preconceitos individuais" Yuval Harari

O filósofo camaronês Achille Mbembe (2014), caracteriza o período neoliberal como "uma fase da história da Humanidade dominada pelas indústrias do silício e pelas tecnologias digitais. O neoliberalismo é a época ao longo da qual o tempo (curto) se presta a ser convertido em força reprodutiva da forma-dinheiro". Na modernidade, o novo homem "não tem, a priori, nenhum limite para a modificação da sua estrutura biológica e genética" (MBEMBE, 2014, p. 14-15; grifo do autor). Diante disso, aberta a possibilidade de comprar as características genéticas dos descendentes, despender altas quantias financeiras em prol da excelência biológica poderá ser eticamente justificado?

Tal apontamento é importante, uma vez que, para Habermas (2010, p. 41) "podemos conceber a autotransformação genética da espécie como o caminho para o aumento da autonomia 
do indivíduo". Entretanto, neste contexto, o que pode ser entendido como autonomia? Embora se admita que a humanidade já está "melhorando" a própria espécie, um processo eugênico permitiria classificar, por raças, categorias distintas de seres humanos, a partir de características específicas. Logo, ao se considerar que a abordagem se dá numa perspectiva pós-metafísica, suspeitamos que o questionamento acerca do futuro da humanidade ganha contornos racistas.

Foucault (2005, p. 304-305) vai ao encontro dessa inferência:

Com efeito, que é o racismo? É, primeiro, o meio de introduzir afinal, nesse domínio da vida de que o poder se incumbiu, um corte: o corte entre o que deve viver e o que deve morrer. No contínuo biológico da espécie humana, o aparecimento das raças, a distinção das raças, a hierarquia das raças, a qualificação de certas raças como boas e de outras, ao contrário, como inferiores, tudo isso vai ser uma maneira de fragmentar esse campo do biológico de que o poder se incumbiu: uma maneira de defasar, no interior da população, uns grupos em relação aos outros. Em resumo, de estabelecer uma censura que será do tipo biológico [...]. Essa é a primeira função do racismo: fragmentar, fazer censuras no interior desse contínuo biológico a que se dirige o biopoder.

O alemão Hans Jonas (2006) considera que o desenvolvimento das técnicas, a partir da possibilidade do homo faber manipular a própria genética, possibilitaram o rompimento dos determinismos naturais, tendo como resultado a aparência da plena liberdade. Contudo, seria imprudente desconsiderar que a própria definição de "liberdade" é passível de discussão ${ }^{8}$.

De todo modo, presume-se que um intelecto mais desenvolvido oportuniza benefícios ao indivíduo melhorado, mesmo a partir da admissão de que os critérios existentes parecem não se aplicar ao novo ser hipotético. Salienta-se, portanto, que a falta de clareza quanto aos critérios que determinam o que se considera como "natureza humana" pode determinar os fatores qualitativos que caracterizariam seres humanos de primeira e/ou de segunda categoria.

Mbembe (2014, p. 119) recorda, ao encontro de Foucault (2005), que desde o período colonial "a Humanidade está dividida em espécies e subespécies, que podemos diferenciar, separar e classificar hierarquicamente". Assim, defendemos que as condições sociais e oportunidades de desenvolvimento econômico são questões relevantes quando se debate acerca do melhoramento da condição biológica humana. Conforme aponta Habermas (2010, p. 57), “a tecnicização da natureza humana altera a compreensão ética da espécie de tal modo que não possamos mais nos compreender como seres vivos eticamente livres e moralmente iguais, orientados por normas e fundamentos".

Foucault (2005, p. 308) sustenta que o racismo "assegura a função da morte na economia do biopoder, segundo o princípio de que a morte dos outros é o fortalecimento biológico da própria pessoa". Nessa perspectiva, o poder é sustentado a partir da introdução e da ativação do preconceito racial e social, uma que "o racismo é ligado ao funcionamento de um Estado que é obrigado a utilizar a raça, a eliminação das raças e a purificação da raça para exercer seu poder soberano" (FOUCAULT, 2005, p. 309).

Sandel (2013, p. 62) ainda aponta outra consequência: a diminuição da solidariedade para com os menos afortunados. $O$ autor defende que um ser humano geneticamente modificado desconhece a natureza do acaso e, portanto, possui menos motivos, para compartilhar a vida com aqueles que não foram projetados. Para o autor,

\footnotetext{
${ }^{8}$ Emmanuel Lévinas (1993) diz que cada sujeito tem responsabilidade acerca da própria vontade, isto é, todos possuem a chamada condição de liberdade. Thomas Hobbes (2004) acredita que a noção de liberdade é subjetiva e ela se caracteriza pela ausência de quaisquer impeditivos que possam limitar ações. Joel Feinberg (1974) sustenta que liberdade difere de satisfação de desejos. Isaiah Berlin (1981) salienta que liberdade não se assemelha à igualdade ou à felicidade. John Rawls (2008) estabelece diversas liberdades, tais como liberdade de pensamento, liberdade de consciência, liberdade individual e liberdade civil.
} 
o melhoramento genético dificultaria o cultivo dos sentimentos morais que a solidariedade social requer. Por que, afinal de contas, os bem-sucedidos devem algo aos membros menos favorecidos da sociedade? Uma resposta sedutora se apoia pesadamente na noção de dádiva. Os talentos naturais que permitem que os bem-sucedidos floresçam não são responsabilidade única deles, mas sim fruto de sua boa sorte — resultado da loteria genética. Se nossas cargas genéticas são uma dádiva, e não uma conquista creditada a nós, é um erro e um preconceito supor que merecemos todas as recompensas que elas proporcionam numa economia de mercado. Logo, temos a obrigação de dividir essas recompensas com aqueles que, por motivos alheios a eles mesmos, não têm dons comparáveis. Eis, portanto, a relação entre solidariedade e dádiva: ter um senso vívido da contingência de nossos dons — a consciência de que nenhum de nós é completamente responsável pelo próprio sucesso — impede a sociedade meritocrática de deslizar para a crença arrogante de que o sucesso é o coroamento da virtude, de que os ricos são ricos porque são mais merecedores do que os pobres. (SANDEL, 2013, p. 64)

Por fim, Foucault (2005, p. 314) recorda que a eliminação econômica não necessita do racismo, para se sustentar. A eliminação biológica, por sua vez, é sustentada pelo racismo. Logo, com a possibilidade de manipulação genética e consequente escolha das características hereditárias, abre-se um novo debate: os humanos do futuro terão autonomia acerca da escolha da própria raça?

\section{O pós-humanismo}

Quando se conjectura acerca de um possível processo de eugenia, não raramente, o termo "pós-humano" se apresenta. As acepções redefinem o conceito de humano com implicações em diversas esferas, sejam elas social, cultural, política ou econômica. Logo, antes de avançar na argumentação, examina-se, brevemente, os pressupostos antropológicos que balizam o termo. Isso se faz fundamental, para justificar o que se entende por "humano". Destaca-se que tais pressupostos são discutíveis e não universalmente reconhecidos, visto que eliminam a possibilidade de autonomia moral dos indivíduos.

O primeiro deles é o reducionismo biológico, isto é, a redução dos conceitos "natureza humana" e "homem" a matéria. O ser humano é considerado um complexo mecanismo material que funciona de forma mecanicista. Este reducionismo, também, se dá no nível neuronal, a partir da decifração do funcionamento do cérebro.

O segundo é a completa eliminação da personalidade com a redução do homem à racionalidade, isto é, do ser à consciência (só é humano quem raciocina). É a derivação do conceito de "pessoa". Desconsidera-se, portanto, embriões, fetos, pessoas em estado vegetativo, em coma ou deficientes mentais.

O terceiro (e mais problemático) pressuposto antropológico é a incapacidade de compreender o sentido da dignidade ontológica humana. $O$ fenômeno se dá a partir da afirmação de que seres humanos são mais complexos, apenas, quantitativamente em relação aos animais ou até mesmo aos objetos e às máquinas. Deste modo, dignidade vincula-se, subjetivamente, à perfeição física e à felicidade psicológica.

Sandel (2013, p. 66) preocupa-se com as consequências dos melhoramentos na mentalidade dos seres projetados, bem como no modo de vida da humanidade do futuro, na qual o autor projeta como sendo menos autônoma.

É tentador pensar que projetar nossos filhos e nós mesmos para o sucesso por meio da bioengenharia é um exercício de liberdade numa sociedade competitiva. Porém modificar 
nossa natureza para nos encaixar no mundo, e não o contrário, é, na verdade, a forma mais profunda de enfraquecimento da autonomia. (SANDEL, 2013, p. 67).

Salienta-se, portanto, que tais pressupostos dificultam a reflexão filosófica acerca do dilema ético-moral, pois, excluem as condições de (a) liberdade, (b) autonomia e (c) dignidade. Logo, se a natureza humana não está condicionada à perfeição genética, há de estar relacionada à constituição individual. Portanto, parece irresponsável desconsiderar o impacto social ocasionado pelos melhoramentos genéticos, pois, se o ser humano não é somente matéria, tampouco age, apenas, racionalmente, qual seria o combustível do desejo da eugenia da espécie humana?

"Nada impede que, num futuro mais ou menos distante, as técnicas genéticas sejam utilizadas para controlar a qualidade de populações e afastar [...] as raças consideradas "indesejáveis". (MBEMBE, 2014, p.46). Assim, ao considerarmos a sociedade como um complexo sistema que se autodesenvolve constantemente parece adequado, antes de vislumbrar o futuro, cogitar cenários possíveis em um contexto socioeconômico excludente.

\section{A africanização genética}

"Quando aquilo que começou no sangue termina no sangue, as hipóteses de um recomeço são enfraquecidas e ensombradas pelo horror do passado" Achille Mbembe

Hipoteticamente, suponhamos que os critérios que determinariam a eugenia humana, sem exceções, definissem que um indivíduo geneticamente modificado, necessariamente, devessem atender às seguintes premissas: (a) nascer negro e (b) habitar a África, continente historicamente caracterizado pelas precárias condições de sobrevivência, tais como a ausência de alimentação adequada e itens básicos, necessários para higiene, vestimenta e transporte. Diante destes balizadores, ainda é possível cogitar um desenvolvimento extraordinário desse hipotético ser humano melhorado?

Pondera-se acerca dos pressupostos elencados a partir da identificação de um processo de "africanização" do mundo, visto que, de acordo com Mbembe (2014, p. 18) "pela primeira vez na história humana, o nome Negro deixa de remeter unicamente para a condição atribuída aos genes de origem africana durante o primeiro capitalismo". Como explica o autor, os termos "raça" e "classe" foram se originando mutuamente.

A raça não existe enquanto fato natural, físico, antropológico ou genético. A raça não passa de uma ficção útil, de uma construção fantasista ou de uma projeção ideológica cuja função é desviar a atenção de conflitos antigamente entendidos como mais verossímeis a luta de classes ou a luta de sexos, por exemplo. (MBEMBE, 2014, p. 26-27).

Ou seja, a partir da hipótese de um processo de modificação genética, condicionado pela cor da pele, isto é, nascer negro (a), defendemos que seria impossível desvincular a representação histórica da exclusão, visto que o negro ainda é, erroneamente, vinculado à submissão social.

"Negro" é, antes de mais, uma palavra [...]. Uma palavra existe para evocar alguma coisa na consciência daquele a quem é endereçada ou que a ouve. Quanto mais densidade e espessura tem, mais a palavra provoca uma sensação, um sentimento e até um ressentimento a quem se destina [...]. "Negro" é portanto o nome que me foi dado por alguém. Não o escolhi originariamente, herdo este nome pela posição que ocupo no mundo. (MBEMBE, 2014, p. 255-256). 
Quanto à localização geográfica, isto é, (b) habitar a África, também pondera-se quanto à impossibilidade de desvinculação primária do território à "precariedade", visto que "África" é o nome que geralmente outorgamos às sociedades consideradas impotentes, isto é, [...] aos nossos olhos, a vida por lá simplesmente nunca será uma vida humana" (MBEMBE, 2014, p. 93-94). Mbembe (2013, p. 23) salienta que centenas de milhões de africanos possuem o desejo de abandonar aquele continente e "viver em qualquer outro lugar do mundo que não o seu". Ademais, ainda segundo Mbembe (2013, p.26), “África continua a ser uma região do mundo onde o poder, de qualquer tipo, sob a chancela do sátrapa, se reveste automaticamente de imunidade. O poderio é uma lei em si mesma".

Nesta perspectiva, considerando que o neoliberalismo contribui, para que grande parte da Terra se assemelhe ao "berço da humanidade", de que forma pode-se discutir um processo de eugenia quando as condições socioeconômicas territoriais condicionam as possibilidades de escolha?

Estamos condenados a viver não apenas com aquilo que produzimos, mas também com o
que herdamos, e devemos aprender a viver tudo isso em liberdade. Uma vez que não
saímos inteiramente de uma mentalidade dominada ainda pela ideia da seleção entre
diferentes tipos de seres humanos, é preciso trabalhar com e contra o passado, de maneira
a que este possa abrir-se para um futuro comum, com dignidade para todos. (MBEMBE,
2014, p. 296).

É exagero pensar que o futuro daqueles que não têm condições de melhorar a carga genética será o afastamento dos demais, sendo realocados em ambientes pré-definidos socialmente? Não parece absurdo supor que, em um futuro próximo, pessoas não modificadas sejam enquadradas em subclasses de seres humanos, condicionadas à existência precária, sujeitos a viver à margem daquilo que é considerado miserável.

Ademais, não se descarta um futuro de perseguições, detenções e até deportações de pessoas, consideradas geneticamente inferiores. Tais questionamentos são importantes uma vez que, como recorda Mbembe (2013, p.42) "para centenas de milhares de descendentes de escravos no Novo Mundo, a prisão tomou rapidamente o lugar da plantação". Logo, diante dos pressupostos estabelecidos, crê-se que o melhoramento genético de um negro em "África" não cessaria a "implementação de políticas de reparação orientadas para a superação de séculos de negligência" (MBEMBE, 2013, p. 48).

Sustento que a crítica em torno do processo de manipulação genética é necessária, pois abre a possibilidade de se debater acerca do reconhecimento mútuo como condição de vida, acima da identificação das raças. (MBEMBE, 2013, p. 94-95). Ademais, recordamos que, para Habermas (2010), os dilemas morais são relativos e baseiam-se na convivência baseada em normas justas, uma vez que "somente as pessoas nascidas, e não as produzidas, encontram-se em interações sociais" (HABERMAS, 2010, p. 90).

Lembramos que Mbembe (2013, p. 93-94), defende que "cidadão é acima de tudo aquele, ou aquela, que está ciente de que é um ser humano igual aos outros e de que, além disso, dispõe da capacidade de discernir a respeito daquilo que é útil para o bem público". $O$ autor acredita que a história de violência e supremacia não negra, no mundo, fez com que o pensamento dominante negasse ou esquecesse que a ascensão à cidadania se dá, justamente, a partir da vinculação de diferenças no espectro do convívio social.

O reconhecimento das diferenças não é muito incompatível com o princípio de uma sociedade democrática. Esse reconhecimento também não significa que a sociedade agora 
funcione desprovida de ideias e crenças comuns. Na realidade, constitui um pré-requisito para que essas ideias e crenças sejam verdadeiramente partilhadas. Afinal, a democracia também significa a possibilidade de identificação com o outro. Sem essa possibilidade de identificação, a República é inativa" (MBEMBE, 2013, p. 97, grifos do autor).

Diante de novas questões, justificamos essa discussão sobre a possibilidade de melhoramento genético humano frente ao debate acerca da questão racial. Tais questões se fazem necessárias, para argumentar sobre a autonomia visto que, a liberdade individual é determinada por "capacidades, disposições e qualidades condicionadas geneticamente" (HABERMAS, 2010, p. 84).

O biodireito, isto é, o conjunto de diretrizes que objetiva normatizar a utilização da biotecnologia e os possíveis impactos na vida humana, se apresenta como uma alternativa para responder tais problemas. Contudo, diante das dificuldades de, até mesmo, conceituar o termo, é provável testemunharmos debates com interpretações hermenêuticas que, evidentemente, estarão em desacordo ético-moral. Por fim, é fundamental ter em mente aquilo que parece ser a herança de toda geração: a lembrança do passado dará o tom da responsabilidade individual que cada cidadão terá na relação com o outro, uma vez que este deverá ser o ponto de partida para a defesa da justiça e da democracia do futuro (MBEMBE, 2013, p. 99).

Como apresentado desde o princípio da reflexão filosófica, buscou-se realizar uma análise biopolítica do racismo, a partir de pressupostos bioéticos, para identificar uma possível eugenia da sociedade moderna. Ademais, questionamos a possibilidade de, num futuro próximo, a dignidade humana estar condicionada à prévia aprovação genética e alertamos que a promessa do aperfeiçoamento individual pode servir de premissa para uma seleção de características desejáveis a partir de padrões previamente estabelecidos via eugenia. Logo, defendemos que as condições sociais e oportunidades de desenvolvimento econômico são questões relevantes quando se debate acerca do melhoramento da condição biológica humana. Assim, sustentamos que a crítica em torno do processo de manipulação genética é necessária e urgente, pois abre a possibilidade de se debater acerca do reconhecimento mútuo como condição de vida, acima da identificação das raças. 


\section{Referências}

BERLIN, Isaiah Sir. Quatro ensaios sobre a liberdade. Brasília: UNB, 1981.

CRARY, Jonathan. 24/7: Capitalismo tardio e os fins do sono. São Paulo: Ubu Editora, 2016. FEINBERG, Joel. Filosofia social. Rio de Janeiro: Zahar, 1974.

FOUCAULT, Michel. Em defesa da sociedade: curso no Collège de France (1975-1976). São Paulo: M. Fontes, 2005.

HABERMAS, Jürgen. O futuro da natureza humana. 2.ed. São Paulo: WMF Martins Fontes, 2010. HARARI, Yuval Noah. 21 lições para o século 21. São Paulo: Cia. das Letras, 2018.

HOBBES, Thomas. Do cidadão. São Paulo: M. Claret, 2004.

JONAS, Hans. O princípio da responsabilidade: ensaio de uma ética para a civilização tecnológica.Trad.: Marijane Lisboa, Luiz Barros Montez. Rio de Janeiro: PUC-Rio, 2006.

LÉVINAS, Emmanuel. Humanismo do outro homem. Petrópolis, RJ: Vozes, 1993.

MBEMBE, Achille. Crítica da razão negra. 2. ed. Lisboa: Antígona, 2014.

MBEMBE, Achille. Sair da Grande Noite. Ensaio sobre a África descolonizada. Luanda: Edições Pedago. 2013

MOORE, George Edward. Princípios éticos. São Paulo: Abril Cultural; 1975.

RAWLS, John. Uma teoria da justiça. 3. ed. rev. São Paulo: Martins Fontes, 2008.

SANDEL, Michael J. Contra a perfeição: ética na era da engenharia genética. 1. ed. Rio de Janeiro: Civilização Brasileiro, 2013.

Contribuição dos(as) autores(as) / Author's Contributions:: Produzido por Eduardo Borile Júnior, o texto foi apresentado como requisito parcial para obtenção do título de Especialista em Bioética pelo Programa de PósGraduação em Filosofia da Universidade de Caxias do Sul, sob orientação bibliográfica do prof. André Brayner de Farias e do prof. Luis Fernando Biasoli, responsável pela revisão e aprovação do aluno no curso referido. Ambos(as) aceitaram e aprovaram a versão final do texto.

Autor(a) para correspondência / Corresponding author: Eduardo Borile Júnior. ebunior1@ucs.br 